\title{
Health Canada "passes the buck" on diabetes drug, researcher charges
}

$\mathrm{H}$ ealth Canada's decision to restrict the use of the diabetes drug rosiglitazone (Avandia) does not go far enough and simply places the responsibility for its safe usage on doctors, a leading critic charges.

"My take is that Health Canada passed the buck to front-line clinicians," says Dr. David Juurlink, a scientist with the Institute of Clinical Evaluative Science and the head of clinical pharmacology and toxicology at the Sunnybrook Health Sciences Centre in Toronto, Ontario.

Health Canada posted a "Dear Doctor" letter from rosiglitazone's manufacturer GlaxoSmithKline Inc. on Nov. 19 which advises physicians to restrict the use of Avandia to those patients for whom all other treatments to control their blood sugar have failed or are not appropriate. In addition, Health Canada now requires doctors to get patients who continue to take rosiglitazone to sign a consent form stipulating that they are aware of the potential risks.

"They've complicated the lives of patients and doctors with a consent form," says Juurlink, who had urged suspension of the drug (www.cmaj.ca /cgi/doi/10.1503/cmaj.109-3268). "To me, it's an ineffective and weak-kneed response."

Health Canada's advisory mirrors that of the United States Food and Drug Administration (FDA), which after conducting hearings into the safety of rosiglitazone in September voted to allow the drug to remain on the market, although with similar tight restrictions. The drug has been implicated in increased cardiovascular events, such as heart attack and stroke.

The FDA also halted a clinical trial, known as TIDE (Thiazolidinedione Intervention with Vitamin D Evaluation), which was to have compared rosiglitazone to pioglitazone and standard diabetes drugs.

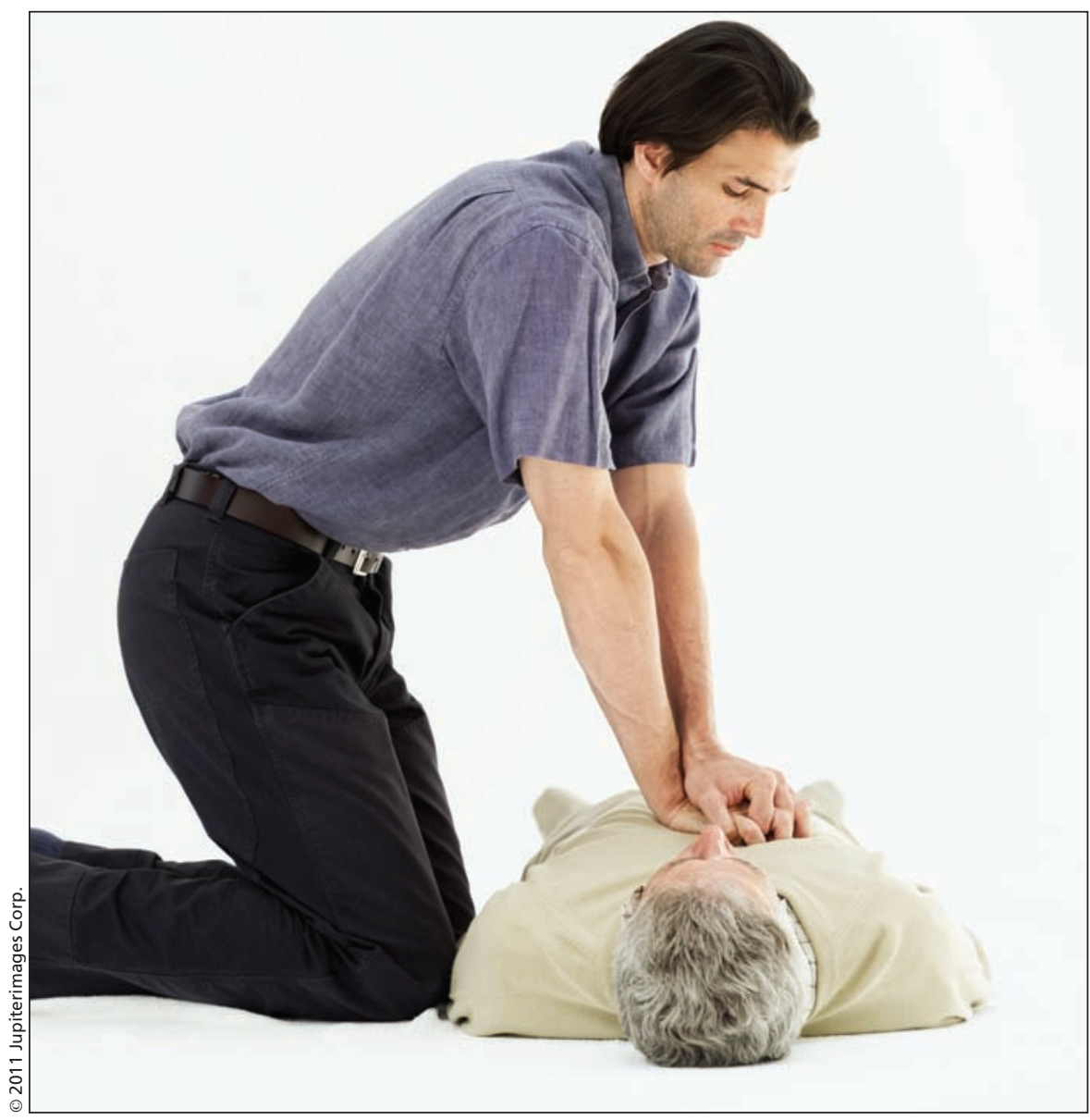

Studies have linked the use of rosiglitazone with increased cardiovascular events, such as heart attack and stroke.

Juurlink believes Health Canada should have followed the lead of the European Medicine Agency, which pulled rosiglitazone off the market.

"The Europeans did the right thing," says Juurlink, who conducted a large study comparing rosiglitazone with pioglitazone, another diabetes drug. "What we have is a regulator that's unwilling to take decisive action, in this case on a drug that not a single Canadian patient needs. Why can't they simply have the guts to pull a drug from the market?"

Health Canada declined interview requests but in a written response states that "no decision to remove a product from the market is taken lightly; it is based on a thorough review of the scientific evidence and scientific evaluation of the product's benefits and risks to Canadians."

Health Canada reviewed scientific data and Canadian adverse reaction reports, as well as "other information," the department added.

"Should new safety information arise, Health Canada will take appropriate action as necessary," the department writes, adding it is tracking adverse cardiovascular events associated with rosiglitazone, as well as doctors' prescribing patterns.

Many doctors are unaware of the 
Health Canada restrictions and are continuing to prescribe rosiglitazone, says Juurlink. "I've had three patients in the last month come in on a formulation of rosiglitazone. Clinicians are too busy to read everything that comes across their desk from Health Canada. They don't listen to what Health Canada has to say unless Health Canada actually does something."

Juurlink's contention that physicians' do not uniformly react to regulatory advisories is supported by data from IMS Health's National Prescription Audit and the Xponent Database.
The data was published in an opinion piece that asserts there were regional variations in rosiglitazone prescribing following the FDA's 2007 "black box" warning about increased cardiovascular risks associated with use of the drug (N Engl J Med 2010; 363:2081-84). While overall use dropped dramatically, rosiglitazone was still prescribed more in some states, such as Oklahoma, than others, such as North Dakota.

Meanwhile, the FDA and Health Canada's restrictions on rosiglitazone use strengthen the position of plaintiffs in a class action lawsuit against Glaxo-
SmithKline, says Saskatchewan lawyer Tony Merchant. "We're feeling better about the case and the strength of the case as a result of Health Canada's decision."

Of the 500 patients or their families who have contacted Merchant's firm, about 50 cases have involved a death, Merchant says. Although the drug company has settled some rosiglitazone lawsuits in the US, they have not made settlement offers in Canada. - Laura Eggertson, Ottawa, Ont.

CMAJ 2011. DOI:10.1503/cmaj.109-3762 